\title{
Pattern and Outcome of Congestive Heart Failure in the Intensive Care Unit of the Yaoundé University Teaching Hospital: A Cross-Sectional Study
}

\author{
Sylvie Ndongo Amougou ${ }^{1,2 *}$, Dieudonné Danwe1, Ba Hamadou ${ }^{1,3}$, Bonaventure Jemea ${ }^{2,4}$, \\ Ahmadou Musa Jingi ${ }^{1}$ \\ ${ }^{1}$ Department of Internal Medicine, Faculty of Medicine and Biomedical Sciences, University of Yaoundé I, Yaoundé, Cameroon \\ ${ }^{2}$ University Teaching Hospital, Yaoundé, Cameroon \\ ${ }^{3}$ Central Hospital, Yaoundé, Cameroon \\ ${ }^{4}$ Department of Surgery and Specialties, Faculty of Medicine and Biomedical Sciences, University of Yaoundé I, Yaoundé, \\ Cameroon \\ Email: *ndongoamougou@yahoo.fr
}

How to cite this paper: Amougou, S.N., Danwe, D., Hamadou, B., Jemea, B. and Jingi, A.M. (2018) Pattern and Outcome of Congestive Heart Failure in the Intensive Care Unit of the Yaoundé University Teaching Hospital: A Cross-Sectional Study. Open Access Library Journal, 5: e4247.

https://doi.org/10.4236/oalib.1104247

Received: December 12, 2017

Accepted: January 12, 2018

Published: January 15, 2018

Copyright $\odot 2018$ by authors and Open Access Library Inc.

This work is licensed under the Creative Commons Attribution International License (CC BY 4.0).

http://creativecommons.org/licenses/by/4.0/

\begin{abstract}
Background: There is paucity of data on congestive heart failure (CHF) in the intensive care unit in our setting. This study aimed to provide a better knowledge of pattern and outcome of CHF in the intensive care unit of the Yaounde University Teaching Hospital. Methods: We carried out a descriptive and retrospective study over a period of 21 months. We collected sociodemographic, clinical, paraclinical outcome and medication data from patients' files. Statistical analysis was done using SPSS Version 20.0 Software. Results: We included 24 patients in this study. CHF represented $6.7 \%$ of admissions in the ICU. The sex ratio was 1 . The mean age was $62 \pm 16$ years. The most frequent comorbidity was hypertension (50\%). Most of the patients (84.6\%) were classified Stage IV according to the NYHA. Dyspnea on exertion was the most frequent symptom (87\%), while bilateral fine crackles were the main findings on physical exam (75\%). Atrial fibrillation was the most frequent abnormality on ECG (53.3\%), and most of the patients had a severe decrease in LVEF (87.5\%). The mean duration of hospital stay was 10 days. In hospital, mortality was $25 \%$, and this was significantly associated with mean blood pressure $<80 \mathrm{mmHg}(\mathrm{p}=\mathbf{0 . 0 4 5})$. Conclusion: Clinical patterns of $\mathrm{CHF}$ in the ICU differed from those found in standard hospital care. Mean blood pressure was significantly associated with outcome. These characteristics should be taken in account while planning the treatment of these patients.
\end{abstract}




\section{Subject Areas}

Cardiology

\section{Keywords}

Pattern, Outcome, Congestive Heart Failure, Intensive Care Unit

\section{Introduction}

Congestive heart failure $(\mathrm{CHF})$ represents a major public health problem in sub-Saharan Africa [1] [2]. Although there is a lack of national level data on disease trends in these countries, several hospital based studies have shown that CHF has a hospital prevalence in internal medicine services of at least 30\% [3] [4] [5]. The hospital mortality varied from one study to another spanning from $9.0 \%$ to $25.9 \%$ [3] [4] [5] [6]. Hypertension is the first risk factor in sub-Saharan Africa, and most of the patients present with systolic dysfunction [3] [4] [5] [6] [7]. Most of these studies have been done in standard cardiology or internal medicine departments. From our knowledge, CHF has never been assessed in the intensive care units (ICU) in Cameroon. We carried out this cross-sectional study to provide a better knowledge of CHF clinical pattern, management and outcome in the ICU of the Yaoundé University Teaching Hospital (YUTH).

\section{Methods}

Study design and setting. We conducted a cross-sectional descriptive and retrospective study at the ICU of the YUTH over a period of 21 months from the $1^{\text {st }}$ January 2016 to the $30^{\text {th }}$ September 2017. The YUTH is one of the four main teaching hospitals in the city. The ICU has an eight bed capacity, staffed with a dedicated team of Intensivists and Cardiologists. Yaounde is the political capital of Cameroon, with a population of about 2 million inhabitants.

Participants and measurements: We included patients aged $>18$ years, of both sex, admitted in the ICU for CHF from the $1^{\text {st }}$ January 2016 to the $30^{\text {th }}$ September 2017 based on admission register. Their medical records were consulted for sociodemographic characteristics, comorbidities, symptoms and signs, electrocardiographic (ECG) and Doppler echocardiographic findings, clinical outcomes as well as medications at discharge. Patients whose medical records were missing where excluded from the study. Left ventricular ejection fraction (LVEF) was classified as preserved ( $>50 \%)$, moderately altered (40\% to $49 \%)$ and decreased $(<40 \%)[8]$.

Sample size and Statistical analysis: The sample size was a convenient sample of all eligible cases of CHF admitted in the ICU of the YUTH. The data collected were analyzed using the Statistical Package for Social Sciences (SPSS) version 20.0 software. Results are expressed as counts and percentage for qualitative variables, and as mean and standard deviation, minimum and maximum for quan- 
titative variables. We assessed the odds of poor outcome in univariate analysis. A $\mathrm{p}$ value $<0.05$ was considered statistically significant for the observed associations.

Ethical considerations: This study was approved by the institutional review board of the Faculty of Medicine and Biomedical Sciences, University of Yaounde 1. Administrative authorization was obtained from the hospital. We carried out this work in accordance with the declarations of Helsinki. We report this work according to the STROBE checklist.

\section{Results}

During the study period, 37 patients where admitted for CHF. The files of 13 patients $(35.0 \%)$ were unexploitable or missing. CHF represented $6.7 \%$ of admissions in the ICU during the same period. Men and women were equally represented. The mean age was $62 \pm 16$ years. The most frequent comorbidities were hypertension (50.0\%), HIV/AIDS (20.8\%), diabetes and chronic kidney disease (12.5\% respectively) [Table 1]. Dyspnea on exertion was the most frequent symptom (87\%) followed by asthenia (83.3\%) and lower limb edema (50\%) [Figure 1]. The majority of the patients (84.6\%) were classified stage IV

Table 1. Comorbidities present in the study population.

\begin{tabular}{ccc}
\hline Comorbidities & Frequency & Percentage (\%) \\
\hline Hypertension & 12 & 50.0 \\
HIV infection & 5 & 20.8 \\
Diabetes & 3 & 12.5 \\
CKD & 3 & 12.5 \\
Viral hepatitis & 2 & 8.3 \\
Total & 24 & 100 \\
\hline
\end{tabular}

HIV = human immunodeficiency virus; $\mathrm{CKD}=$ chronic kidney disease.

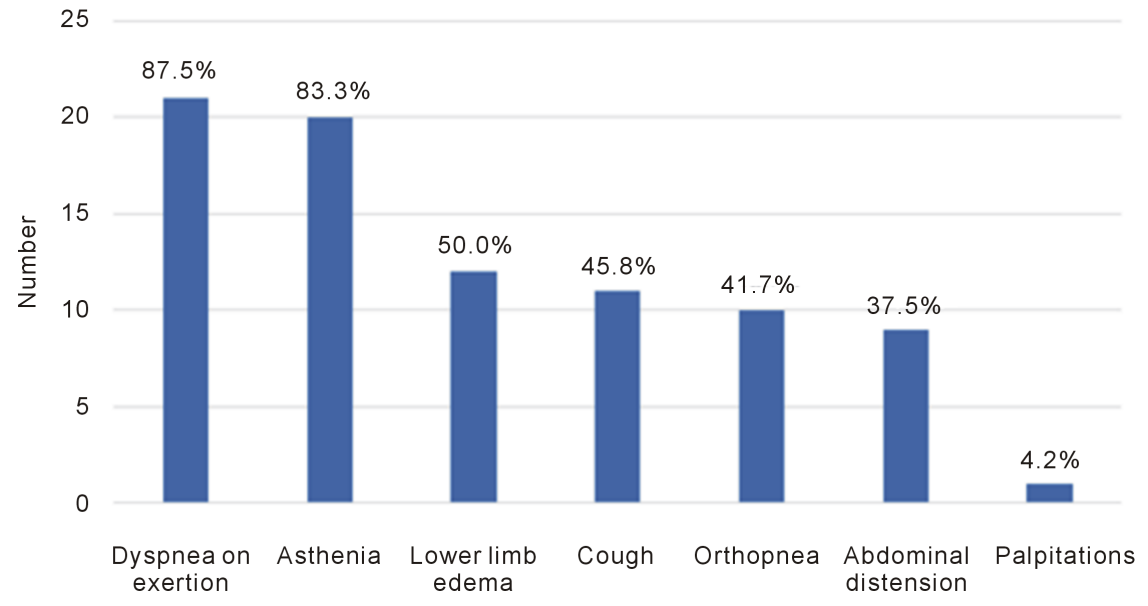

Figure 1. Symptoms of heart failure. 
according to the New York Heart Association (NYHA) classification of CHF, and $15.4 \%$ at stage III. Physical signs were predominantly bilateral fine lung crackles (75\%), hepatomegaly, ascites and lower limb edema ( $45.8 \%$ respectively) [Figure 2]. The main anomalies on the ECG were atrial fibrillation (53.3\%) and ventricular premature beats (46.7\%). Most patients had a decreased LVEF (87.5\%), while only one patient had a preserved LVEF [Table 2]. The cardiac disease in our series was mainly dilated cardiomyopathy [Table 3]. The mean duration of hospital stay was 10 days, ranging from 1 to 26 days. In hospital mortality was $25 \%$. Low mean blood pressure was significantly associated with poor outcome [Table 4]. At discharge, surviving patients received loop diuretics (100\%), digitalis (66.7\%), angiotensin converting enzyme inhibitors/angiotensin receptor blockers (50\%) and beta-blockers (16.7\%) [Figure 3].

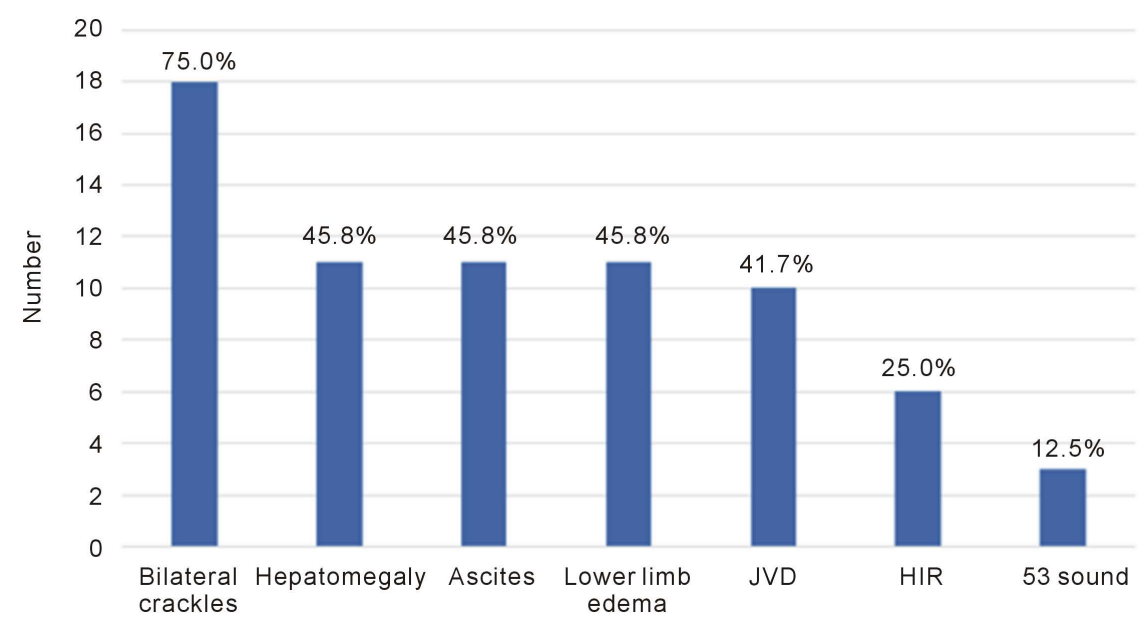

Figure 2. Physical signs of heart failure (JVD = jugular venous distention; HJR = hepatojugular reflux).

Table 2. Classification according to the Left Ventricular Ejection Fraction (LVEF).

\begin{tabular}{ccc}
\hline LVEF (\%) & Frequency & Percentage (\%) \\
\hline$<40$ & 14 & 87.5 \\
$40-49$ & 1 & 6.2 \\
$\geq 50$ & 1 & 6.2 \\
Total & 16 & 100 \\
\hline
\end{tabular}

LVEF = left ventricular ejection fraction.

Table 3. Types of heart diseases from the results of echocardiography.

\begin{tabular}{ccc}
\hline Type of heart disease & Frequency & Percentage (\%) \\
\hline Dilated cardiomyopathy & 11 & 68.8 \\
Ischemic cardiomyopathy & 4 & 25.0 \\
Hypertrophic cardiomyopathy & 1 & 6.2 \\
Total & 16 & 100 \\
\hline
\end{tabular}


Table 4. Factors associated with in hospital mortality.

\begin{tabular}{ccccc}
\hline Variable & Alive, n (\%) & Dead, n (\%) & OR (CI 95\%) & P value \\
\hline Age (years) & & & & \\
$\geq 60$ & $13(72.2)$ & $3(50.0)$ & $2.60(0.39-17.45)$ & 0.302 \\
$<60$ & $5(27.8)$ & $3(50.0)$ & & \\
Gender & & & & \\
Male & $9(50.0)$ & $3(50.0)$ & $1.00(0.16-6.35)$ & 0.680 \\
Female & $9(50.0)$ & $3(50.0)$ & & \\
MBP (mmHg) & & & & \\
$<80$ & $3(17.6)$ & $4(66.7)$ & $9.33(1.14-76.69)$ & \\
$\geq 80$ & $14(82.4)$ & $2(33.3)$ & & 0.233 \\
LVEF (\%) & & & & \\
$\leq 25$ & $6(42.9)$ & $2(100.0)$ & & \\
$>25$ & $8(57.1)$ & $0(0.0)$ & & \\
\hline
\end{tabular}

OR: odds ratio; CI: confidence interval; n: number; \%: percentage; MBP: mean blood pressure; LVEF: left ventricular ejection fraction; NA: not applicable.

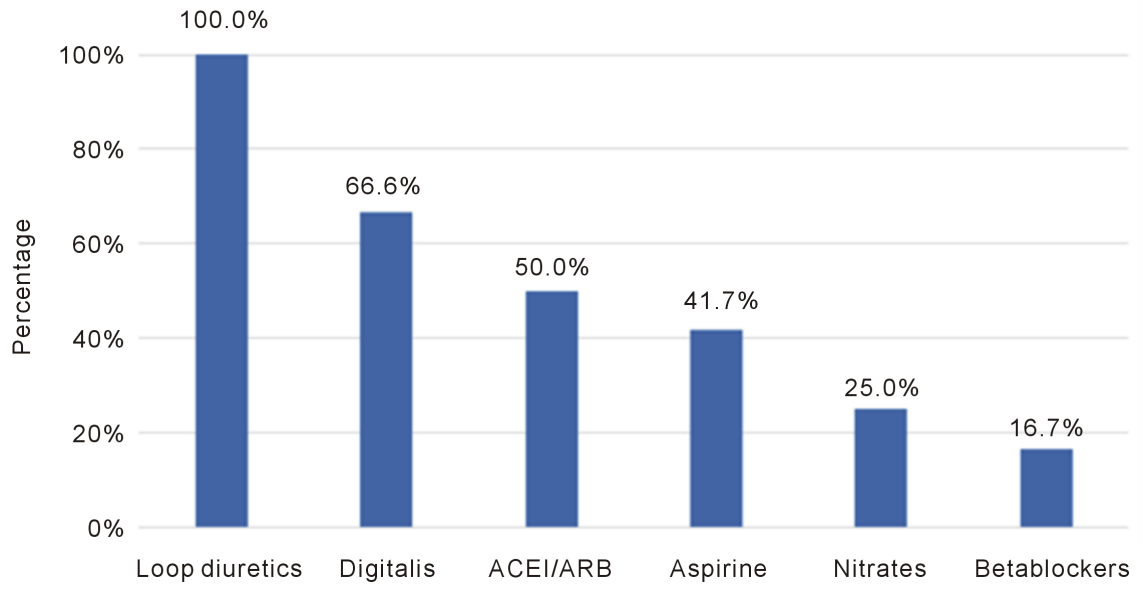

Figure 3. Heart failure drug classes used at discharge (ACEI = angiotensin converting enzyme inhibitors; $\mathrm{ARB}=$ angiotensin receptor blockers).

\section{Discussion}

CHF represented $6.7 \%$ of all admissions in the ICU of the Yaounde University Teaching Hospital. This proportion is far from the 30\% and 33.3\% reported by Kingue et al. [4], and Boombhi et al. [5] at the Cardiology departments of the Yaounde General and Central Hospitals, and can be explained by the fact that the YUTH ICU does not take care of cardiology patients only, but of all patients needing special care, whatever their pathology. The mean age of 62 years is consistent with that reported by Kingue et al. and Boombhi et al. but higher than the 42.5 years reported by Tantchou et al. [6]. The reason is that, many patients in Tantchou et al. series where children who developed CHF secondary to lately diagnosed congenital heart diseases.

The main risk factor found was hypertension (50\%) which is consistent with data reported in the literature [3]-[9]. HIV/AIDS was also an important co-mor- 
bidity (20.8\%). Magula and Mayosi concluded in a review that showed that HIV infection may be as well an etiologic factor of heart disease as an aggravating factor [10].

Dyspnea on exertion was the most frequent presenting complain as found by Kingue et al., Tantchou et al., Pio et al. and Boombhi et al. [4] [5] [6] [7], and the majority of patients were classified stage IV according to the NYHA, pointing to the fact that people consult lately in sub-Saharan Africa.

In our series, bilateral fine crackles were the most common physical sign corroborating with the findings of Boombhi et al., followed by hepatomegaly, while Kingue et al. found that hepatomegaly was the most frequent physical sign [4] [5]. The fact that our patients were at a more advance stage of the disease than theirs may explain this difference in result.

Considering the findings on ECG, atrial fibrillation was the most common abnormality found which is consistent with the results of Boombhi et al., but different from those of Thiam et al., Tantchou et al., and Pio et al., who found ventricular hypertrophy as the main finding [3] [6] [7]. The greater proportion of advanced stages of heart failure in our series, which we know lead to dilatation of heart chambers, and responsible for the appearance of atrial fibrillation is the most probable explanation for this.

As reported in the literature, the majority of patients had systolic dysfunction, with most of them having a decreased LVEF, and Dilated cardiomyopathy the most common type of cardiopathy [4] [6] [7].

The mean duration of hospital stay in our series was 10 days, in concordance with the median 10 days reported in a Haitian series [11]. The hospital mortality of $25 \%$ is comparable to the $18.4 \%$ reported by Boombhi et al. at the Cardiology department of the Yaounde Central Hospital, but far higher than the 9 and 9.2\% reported by Kingue et al., and Tantchou et al. [4] [5] [6]. We had in our series and the one of Boombhi et al. respectively $84.6 \%$ and $65.8 \%$ of patients at stage IV heart failure compared to $7 \%$ in the other series. This suggests that mortality rates increases with the stages of CHF. We also found out that the mean blood pressure was significantly associated with outcome. This suggests that efforts should be made to maintain the above $80 \mathrm{mmHg}$ so as to reduce in-hospital mortality.

There is still little prescription of beta-blockers for heart rate control in sub-Saharan Africa [4] [6], even after a hospital stay in the ICU, as it is in the internal medicine departments of hospitals in this region. Meanwhile, two thirds of the patients in our series were prescribed digitalis upon discharge, far higher than the $30.5 \%$ reported by Kingue et al. [4].

\section{Limitations and Strength}

The main weakness of this study is the retrospective design, resulting in loss of data as the files of patients could not be found. This did not permit us assess the incidence of heart failure in the ICU. The small sample size also reduced the 
power to detect significant associations. Despite these weaknesses, this is the first study of heart failure in the intensive care unit in our setting. We have shown that the mean blood pressure is a determinant of outcome in these groups of patients. This study also paved the way for further studies of heart failure in the ICU in our setting.

\section{Conclusion}

Patten and outcome of CHF in ICU in Cameroon are comparable to those found in internal medicine department with respect to the disease stage. However, most patients were admitted at late stages of the disease in ICU. Low mean blood pressure was significantly associated with poor outcome. Digitalis is used in higher proportions.

\section{Conflict of Interest}

Authors declare no conflict of interest.

\section{Contribution of Authors}

Sylvie Amougou Ndongo, Dieudonné Danwe and Bâ Hamadou designed the study. Dieudonné Danwe, Sylvie Amougou Ndongo and Bonaventure Jeméa collected the data. Dieudonné Danwe did all statistical analysis. Sylvie Amougou Ndongo and Jingi Musa Ahmadou contributed in supervising the study. All the authors have read and agreed with the final version of the manuscript.

\section{Acknowledgements}

We address acknowledgments to the Yaoundé University Teaching Hospital intensive care unit staff members.

\section{References}

[1] Bloomfield, G.S., Barasa, F.A., Doll, J.A. and Velazquez, E.J. (2013) Heart Failure in Sub-Saharan Africa. Current Cardiology Reviews, 9, 157-173. https://doi.org/10.2174/1573403X11309020008

[2] Ntusi, N.B. and Mayosi, B.M. (2009) Epidemiology of Heart Failure in Sub-Saharan Africa. Expert Review of Cardiovascular Therapy, 7, 169-180. https://doi.org/10.1586/14779072.7.2.169

[3] Thiam, M. (2003) Heart Failure in African Cardiologic Medium. Bulletin de la Société de Pathologie Exotique, 3, 217-218.

[4] Kingue, S., Dzudie, A., Menanga, A., Akono, M., Ouankou, M. and Muna, W. (2005) New Look on Chronic Heart Failure of the Adult in Africa at the Era of Doppler Echocardiography: Experience of the Internal Medicine Department of the Yaounde General Hospital. Annales de Cardiologie et d'Angéiologie, 54, 276-283. https://doi.org/10.1016/j.ancard.2005.04.014

[5] Boombhi, J., Moampea, M., Kuate, L., Menanga, A., Hamadou, B. and Kingue, S. (2017) Clinical Pattern and Outcome of Acute Heart Failure at the Yaounde Central Hospital. Oalib, 4, 1-8. https://doi.org/10.4236/oalib.1103478 
[6] Tantchou, T., Ambassa, J., Kingue, S., Giamberti, A., Cirri, S., Frigiola, A., et al. (2011) Occurrence, Aetiology and Challenges in the Management of Congestive Heart Failure in Sub-Saharan Africa: Experience of the Cardiac Centre in Shisong, Cameroon. Pan African Medical Journal, 8. https://doi.org/10.4314/pamj.v8i1.71059

[7] Pio, M., Afassinou, Y., Pessinaba, S., Baragou, S., N'djao, J., Atta, B., et al. (2014) Epidemiology and Etiologies of Heart Failures at Lomé. Pan African Medical Journal, 18.

[8] Ancion, A., D’Orio, V. and Lancellotti, P. (2017) European Recommendations Regarding Management of Chronic Heart Failure. Revue Médicale de Liège, 72, 6873.

[9] Ojji, D.B., Alfa, J., Ajayi, S.O., Mamven, M.H. and Falase, A.O. (2009) Pattern of Heart Failure in Abuja, Nigeria: An Echocardiographic Study. Cardiovascular Journal of Africa, 20, 349-352.

[10] Magula, N.P. and Mayosi, B.M. (2003) Cardiac Involvement in HIV-Infected People Living in Africa: A Review. Cardiovascular Journal of South Africa, 14, 231-237.

[11] Kwan, G.F., Jean-Baptiste, W., Cleophat, P., Leandre, F., Louine, M., Luma, M., et al. (2016) Descriptive Epidemiology and Short-Term Outcomes of Heart Failure Hospitalisation in Rural Haiti. Heart, 102, 140-146.

https://doi.org/10.1136/heartjnl-2015-308451 